\title{
Asklepios: Sy rol in die evolusie van die Geneeskunde
}

\author{
Authors: \\ François P. Retief ${ }^{1}$ \\ Louise Cilliers ${ }^{1}$ \\ Affiliations: \\ ${ }^{1}$ Department of Classical \\ and Near Eastern Studies, \\ University of the Free \\ State, South Africa \\ Correspondence to: \\ Louise Cilliers \\ Email: \\ clouise@mweb.co.za \\ Postal address: \\ PO Box 339, Bloemfontein \\ 9300, South Africa \\ Dates: \\ Received: 10 Oct. 2010 \\ Accepted: 04 Jan. 2011 \\ Published: 06 Apr. 2011 \\ How to cite this article: \\ Retief, F.P. \& Cilliers, L., \\ 2011, 'Asklepios: Sy rol \\ in die evolusie van die \\ Geneeskunde', Suid- \\ Afrikaanse Tydskrif vir \\ Natuurwetenskap en \\ Tegnologie 30(1), Art. \#26, \\ 5 pages. doi:10.4102/satnt. \\ v30i1.26
}

(C) 2011. The Authors. Licensee: OpenJournals Publishing. This work is licensed under the Creative Commons Attribution License.
Asklepios word vir die eerste keer deur Homeros as aanvoerder en geneesheer genoem in die Trojaanse Oorlog. Later, gedurende die 5de eeu v.C. het Asklepios bekend geword as die god van genesing. Dit was ook in hierdie tyd dat die Asklepeïese kultus van genesing in Epidaurus onstaan het. Hierdie helingskultus, wat geakkommodeer is deur die empiriese geneeshere van die tyd, het vir bykans 10 eeue voortbestaan in Asklepieia, waarvan daar meer as 400 in die Mediterreense seegebied en omstreke was. Asklepieia was van verskillende ontwerp, maar het gewoonlik ' $n$ tempel ingesluit wat aan die god gewy is, asook inskripsies [iamata] met inligting van pasiënte wat genees is, ' $n$ heilige bad, ' $n$ put en 'n slaapvertrek [abaton] waar die pasiënt 'n nag van sogenaamde inkubasieslaap deurgebring het. Tradisioneel het Asklepios aan hulle verskyn in ' $n$ nagtelike visioen, en het daar ' $n$ onmiddellike wondergenesing plaasgevind, of is daar raad gegee in verband met die toekomstige behandeling van die siekte, wat daarna deur die tempelpersoneel bespreek is. Daar word beweer dat die Asklepeïese kultus, ' $n$ godsdienstige genesingsprogram, sekulêre behandeling gekomplementeer het deurdat die tempelpersoneel wel in kontak was met die tydgenootlike Hippokratiese geneeskunde. Die emosionele impak van die inkubasieslaap en drome kon 'n genesingsimpak op kwale met 'n sielkundige basis gehad het. Die finale verdwyning van die Asklepeïese kultus was die gevolg van die opkoms van die Christendom as staatsgodsdiens, eerder as die agteruitgang van sy genesingsdoeltreffendheid.

Asclepius is first mentioned by Homer as leader and physician in the Trojan War. Later, during the 5th century, he became known as the god of healing, and in this century the Asclepian cult of healing became established in Epidaurus. This healing cult, which was accommodated by empiric (Hippocratic) physicians of the time, endured for close on ten centuries in Asclepieia, of which there were more than 400 in the Mediterranean area and surrounding countries. The Asclepieia were of different design, but usually included a temple dedicated to the god, as well as inscriptions [iamata] with information on the patients who were healed, a sacred bath, a well and a room [abaton] for so-called incubation sleep where the patient would spend the night. Asclepius traditionally appeared to the patients in a vision in the course of the night and an immediate miraculous healing could take place, or advice was given regarding the future treatment of the patient, which was in the morning thereafter discussed by the temple personnel. It is said that the Asclepian cult, a religious healing programme, complemented secular treatment since the tempel personnel were in contact with contemporary Hippocratic medicine. The emotional impact of the incubation sleep and dreams could have had a healing impact on ailments with a psycological basis. The final disappearance of the Asclepian cult was the result of the rise of Christianity, rather than the decline of its healing effectiveness.

\section{Inleiding}

Asklepios verskyn vroeg reeds in die antieke Griekse era as die god van geneeskunde en die beskermheilige van dokters (Edelstein \& Edelstein 1998:1-66). Sy helingskultus is vir bykans 10 eeue entoesiasties ondersteun. Alhoewel sekere Asklepieia nie dokters ingesluit het nie, was Asklepios nietemin in die Corpus Hippocraticum erken, en die slang-en-staf simbool is tot vandag nog die embleem van die mediese praktyk (Retief \& Cilliers 2002:553-556). In hierdie artikel word die aard van sy helings-praktyk bespreek en sy bydrae tot die evolusie van die mediese wetenskap bepaal.

\section{Die oorsprong van die kultus van Asklepios}

Asklepios maak sy eerste verskyning in die werke van Homeros en Hesiodos, waar hy as leier en geneeskundige beskryf word, afkomstig uit Tricca, Ithone of Dechalia in Thessalië gedurende die Trojaanse Oorlog (Nutton 2004:103-105). Hy is die kleinseun van Zeus, met Apollo as vader en ' $n$ menslike moeder, Coronis. Hy het die geneeskuns by die centaur Chiron geleer en dit aan sy twee seuns, Machaon and Podalirius, oorgedra, wat ook geneeshere en soldate in die Trojaanse Oorlog was. Arctinus (Nutton 2004:38) is van mening dat Machaon 'n chirurg was, 
terwyl Podalirius interne siektes behandel het. Asklepios was getroud met Epione, en het vyf dogters gehad, Hygieia, Panacea, Aceso, Iaso en Aglaea, wat ook by gesondheidsorg betrokke was. Alhoewel die mitologie meer te sê het oor die mediese doen en late van sy seuns, het die medikus Eryximachus (Edelstein 1967:225) later vir Asklepios as die god van dokters en pasiënte bestempel. Ons verneem ook dat Zeus hom uiteindelik met 'n weerligstraal om die lewe gebring het omdat hy te suksesvol in sy beroep was en selfs dooies opgewek het waardeur hy die koning van die gode na die kroon sou steek.

Asklepios se geskiedenis het mettertyd verwarrend geword as gevolg van teenstrydige sienings waarvolgens hy nie in Thessalië gebore sou gewees het nie, maar in die Peloponnesos, of in Messenië of Arkadië. Aristides (Aelius in Levi 1971) skryf dat Asklepios se seuns na Klein-Asië getrek het na die Trojaanse Oorlog. Hier het hulle die gebied van Kos, Knidos en Karia ontwikkel en Egipte se reputasie vir uitstekende mediese kennis en praktyk 'n gevoelige knou toegedien. Teen 369 v.C. is die Delfiese Orakel versoek om die probleem van Asklepios se afkoms op te los, en is die uitspraak gelewer dat alhoewel sy moeder uit Thessalië afkomstig was, hy eintlik in Epidaurus in die Peloponnesos gebore is. Dit het die inwoners van Epidaurus groot vreugde verskaf, en vroeg in die 5de eeu v.C. het dit 'n sentrum geword vir die helingskultus van Asklepios. Hiervandaan het sy kultus verstommend vinnig gegroei van plaaslike god tot pan-Helleense god. Gedurende die 4de eeu het sentrums oral verskyn - van die Peloponnesos tot in Thessalië en Klein Asië (Kos, Pergamum en Efese). In die 3de eeu is heiligdomme opgerig in Sicilië (Syracusae en Agrigentum) en op die Egeïese eilande (Kreta en Lebena). In reaksie op 'n epidemie, is die kultus in 291 v.C. in Rome gevestig. Die kultus het ' $n$ piek bereik in die 2de eeu n.C. met meer as 400 heiligdomme oor die hele Mediterreense gebied. Tydens die Romeinse Ryk was die kultus gewild, maar tempels is toenemend geplunder, alhoewel keisers soos Hadrianus, Antoninus Pius, Marcus Aurelius and Caracalla simpatiek was en selfs gehelp het met herbouing. Die tempels van Pergamum en Kos het belangrike sentrums geword in die 2de en 3de eeue, maar Pergamum is uiteindelik in 253 en 260 deur aardbewings vernietig. Met die koms van die Christendom en die aanvaarding daarvan as staatsgodsdiens aan die einde van die 4de eeu, is die kultus van Asklepios ernstig bedreig en sommige van die tempels vernietig. Die laaste inskripsie in Epidaurus is in 355 n.C. gemaak. (Edelstein \& Edelstein 1998:256), en gedurende die 6de eeu het die kultus opgehou om te bestaan.

Alhoewel die Grieke Asklepios as die spesifieke god van genesing beskou het, is ' $\mathrm{n}$ groot aantal ander gode ook oor gesondheidsprobleme genader, byvoorbeeld Apollo, Artemis, Zeus, Atena, Hermes, Mars en Minerva. Daar was ook skadu-agtige 'helde-geneser'-gode in spesifieke gebiede, byvoorbeeld Trophonius, Amphilochus, Aristomachus, Oresinius en Amphiaraos. Asklepios se reputasie het wyd versprei, en met tyd is hy geassossieer met die gode Imhotep, Isis en Serapis in Egipte, en Eshmun in Fenisië (Nutton 2004:273-274).

\section{Materiaal en metodes Kultus-strukture}

Die strukture wat kultusaktiwiteite in spesifieke gebiede geakkommodeer het is Asklepieia genoem (Edelstein \& Edelstein 1998:233-257). Hulle was gewoonlik, alhoewel nie altyd nie, op aangename, heilsame plekke geleë - en nog belangriker, op plekke waar menslike aktiwiteitsvlakke hoog was. Baie het ontspring as 'n onder-afdeling van die bestaande tempels van ander gode, veral Zeus, Atena en Apollo. Die Asklepieia het in ontwerp verskil vanaf relatief eenvoudige strukture tot manjifieke tempels. Die oorspronklike sentrum by Epidaurus was redelik verteenwoordigend, en was vir 'n lang tyd die gewildste en indrukwekkendste sentrum; dit het ook groot rykdom besit (Nutton 2004:108).

Die Asklepieion by Epidaurus is deeglik beskryf deur Pausanias (1971:1-7). Dit was omtrent $8 \mathrm{~km}$ vanaf die stad geleë in 'n aangename bebosde gebied, wat 'n gewyde gebied geword het. Dit het ' $n$ tempel [cella] ingesluit wat in 'n groot heiligdom geleë was.

Die ingang van die heiligdom was ' $\mathrm{n}$ kolonnade wat aan 'n verdere dubbelverdieping-kolonnade gekoppel was. Die gebou het kamers [abata] bevat vir inkubasieslaap, wat die belangrikste deel van die heiligdom was. Daar was ook altare vir Asklepios sowel as vir ander gode, en 'n groot aantal en verskeidenheid van standbeelde - insluitend dié van die Asklepeïese familie; die god is gewoonlik voorgestel saam met sy vrou, Epione. Daar was ook ander monumente wat geverfde terracotta voorwerpe en ' $n$ indrukwekkende ronde marmergebou [tholos] ingesluit het. Gewyde voorwerpe wat die ervarings van tevrede pasiënte deur middel van inskripsies [iamata], skilderwerk, reliëfwerk en ander strukture weergegee het, was oral te sien. ' $n$ Heilige bad met 'n skouspelagtige dak en kolonnade was oor 'n put geleë. Buite die heiligdom was ' $n$ stadion en 'n manjifieke opelug teater. Die tempel is bereik deur gepoleerde marmertrappe. Die dak was met goud beslaan. In die middel was ' $n$ altaar en ander religieuse voorwerpe, sowel as ' $n$ indrukwekkende kultusstandbeeld van Asklepios deur Thrasymedes uit ivoor en goud gemaak. Die mure was versier met inskripsies en indrukwekkende skilderwerk. Absolute stilte is gehandhaaf en die besoekers het geglo dat die god persoonlik teenwoordig was.

\section{Kultusprosedure}

Persone wat die god weens gesondheidsprobleme wou nader, het dit op verskeie maniere gedoen, waaronder die sogenaamde inkubasieslaap in 'n Asklepieion waarskynlik die bekendste en mees dramatiese was. Meer dikwels het pasiënte egter eenvoudig by die huis of in die tempel tot Asklepios gebid, dikwels in die teenwoordigheid van 'n priester, en miskien met 'n offerande. Soms het die god persoonlik gereageer op die pasiënt se gebed deur die siekte onmiddellik te genees, of anders advies gegee. Daar is ook geglo dat water uit die heilige bad siektes kon genees. Aristides (Oration xlii) het geglo dat Asklepios magte buite 
die gesondheidsveld gehad het en dat hy vermoëns kon skenk in die kunste, redenaarskuns, skryfkuns en leierskap, in liggaamsbou en selfs in boks. Hy kon ook bystand verleen gedurende storms op die see.

Die Asklepieion se genesingsprosedure het gefokus op die inkubasieslaap, alhoewel dit nie slegs in die Asklepeïese kultus voorgekom het nie. Dit het ook deel gevorm van die genesingsproses wat gevolg is deur Trophonius by Ledala, Amphiaraos by Oropos, en die sogenaamde Oosterse misterie-godsdienste (Nutton 2004:110).

Die genesingsprosedure was min of meer dieselfde in al die Asklepieia. Wanneer die besoeker die Asklepieion bereik, het hy geen fooi betaal nie, maar in die heilige put gebad - geen ander reinigingsrituele, spesiale dieet of kleredrag was nodig nie. In die teenwoordigheid van ' $n$ priester is ' $n$ gebed gedoen en 'n offerande gebring. Die offerande was heel eenvoudig en het gewoonlik bestaan uit koek, vye, speserye, blomme, ringe, eenvoudige klere, kerse of vleis (dié van osse, bokke, varke en hane). Wanneer dit donker geword het, het die pasiënt die slaapvertrek [abaton] betree en op 'n lae platvorm sonder 'n bedekking gaan lê. Die fakkels is uitgedoof met die oog op die binnekoms van die god. Verskeie dinge kon dan plaasvind. Die pasiënt kon byvoorbeeld in ' $n$ trans [opsis] gaan of 'n goddelike droom [enhupnion] hê. As die pasiënt gelukkig was, sou Asklepios aan hom of haar verskyn as ' $n$ vriendelike man of aantreklike jongeling, en sy of haar gesondheidsprobleme bespreek. Die god sou miskien selfs aan die pasiënt raak, en by tye sou heilige slange of honde aan hom of haar lek. Die god kon selfs operasies doen, waarvan die pasiënt dan die volgende dag heeltemal genees sou wees alhoewel daar nog bloed op die vloer kon wees. Siekte kon dus onmiddellik deur 'n wonderwerk genees word, maar sedert Hellenistiese tye het dit meer dikwels gebeur dat die pasiënt raad ontvang het ten opsigte van doeltreffende behandeling, dieet of leefstylaanpassing. By tye sou die god 'n raaisel gee wat die volgende oggend met die hulp van die tempelpersoneel opgelos is. Soms het die god nie in ' $n$ droomvisioen verskyn nie, maar het die pasiënt wakker geword met 'n bewustheid van die toepaslike terapeutiese behandeling. Ook dan sou daar die volgende oggend 'n bespreking met die tempelpersoneel wees oor die voorgestelde behandeling. Die priesters het selfs medisyne beskikbaar gehad wat die pasiënt kon gebruik wanneer dit so voorgestel is. Voordat hy of sy die tempel verlaat, het die pasiënt 'n dankoffer gebring, gebid, en gewoonlik 'n donasie aan die priester gegee. Gewyde voorwerpe en geassosieerde inskripsies [iamata] (waarop dankbare pasiënte hul gevoelens in verskeie formate opgestel het), is in die heiligdom gelos en dien vandag as ' $n$ goeie rekord van mediese probleme wat daardie tyd behandel is. Dit is ook moontlik dat tempelpersoneel hulp verleen het met die inligting wat op die iamata aangebring is om te verseker dat toepaslike toegewydheid aan die god betoon word, maar ook om goeie propaganda vir die tempel te maak. Die tempelpersoneel het bestaan uit 'n priester wat in wit geklee was (Pergamum priesters het ook pers gedra) met sy hare in ' $n$ wit filet gebind. Afhangende van die grootte van die betrokke Asklepieion, kon daar ook ander assistente wees. Dokters is nie in Epidaurus in diens geneem nie, maar skynbaar wel in Pergamum en Kos (Edelstein \& Edelstein 1967:158; Herzog 1931:60).

Benewens aktiwiteite wat te doen gehad het met die helingskultus, het die tempel ook gereelde (selfs daaglikse) dienste gehou, waar 'n gemeente en koor deelgeneem het aan die sing van spesiale gesange en offerandes. Aanddienste is prominent verlig deur gewyde kerse. Daar was ook seisoenfeeste (die Asklepieia en Epidauria) wat godsdienstige aktiwiteite sowel as algemene feesvieringe behels het. Spele soos die Olimpiese Spele is elke vyf jaar aangebied, dwarsdeur die antieke tyd. Daar was ook musieken dramafeeste. By Efese was daar vanaf die 2de eeu v.C. gereeld mediese kompetisies gehou waar dokters by die Asklepieion vir pryse gekompeteer het. Vandag is daar nie veel bekend oor hierdie kompetisies nie (Nutton 2004:281).

Die aard van siektes (meestal chronies) wat voorgekom het, kan afgelei word uit 83 inskripsies [iamata] wat deur die Edelstein egpaar versamel is:

- $\quad$ wonde en absesse (13)

- blindheid (12)

- verlamming en lamheid (8)

- vrugbaarheidsprobleme (8)

- gewrigsprobleme (7)

- parasiete (6)

- longsiektes (6)

- gewasse (3)

- 'steen' (2).

'n Heterogene groep (18) het ingesluit:

- hoofpyn

- velvlekke

- pestilensie

- dronkenskap

- dispepsia

- epilepsie

- onbekende siektes.

Ander rekords sluit in dankbaarheid vir die 'genesing' van 'n gebreekte goue glas (4de eeu v.C.) en die terugvind van 'n verlore seun. Uit die geskrifte van die hipokondriese Aelius Aristides (2de eeu n.C.) weet ons dat sommige pasiënte ver gereis het, en ander genoeg vertroue gehad het om gereelde besoeke aan die Asklepieia af te lê. Die omgewing waarin die heiligdomme geleë was, was inderdaad ingerig vir lang en aangename besoeke. Alhoewel pasiënte die heiligdom normaalweg persoonlik besoek het, was dit ook aanvaarbaar om byvoorbeeld in die geval van 'n bejaarde persoon ' $n$ seun in sy plek te stuur (Edelstein \& Edelstein XXI:423; Libanius xxxiv:23-26). Die inskripsies [iamata] vertel nie van mislukte terapie nie, maar mens wil aanvaar dat vele pasiënte nie genees is nie of slegs tydelik genees is - moontlik meer as dié wat wel genees is.'

\section{Resultate}

Kultus, medici en geloof

Die foutiewe siening dat Asklepios die fondament gelê het vir Hippokratiese (empiriese) geneeskunde was algemeen in die 
vroeë antieke tyd. Sekulêre geneeskunde, verteenwoordig deur die Corpus Hippocraticum, het die Asklepioskultus voorafgegaan. Dit was gebaseer op die sienings van vroeëre wetenskapsfilosowe, wat geglo het dat siektes die gevolg was van natuurlike oorsake eerder as bonatuurlike faktore, maar dit kon ook wel goddelike ingryping insluit. Geneeshere uit die vroeë antieke tyd het hulself Asklepiade genoem uit eer vir Homeros se held (later god) van geneeskunde en nie omdat hulle Asklepios se helingskultus ondersteun het nie (Edelstein \& Edelstein 1998:53-58). Die Grieks-Romeinse wêreld het in 'n groot verskeidenheid van gode geglo wat alle aspekte van die lewe beïnvloed het. Die Hippokratiese dokters, alhoewel hulle nie in toordery en die okkulte geglo het nie, het respek vir die goddelike behou en vir Asklepios in die Hippokratiese Eed vermeld. Hierdie onderskeid het die sekulêre medikus in staat gestel om met die Asklepeïese kultus saam te leef wat op geloof in die gode gebaseer was en nie op fisiese beginsels nie. Latere sekulêre medici soos Galenus en Rufus het ook geen vyandskap teenoor Asklepios getoon nie, maar selfs van die kultus se elemente in hul praktyk gebruik. Op sy beurt was die samewerking met die mediese beroep ook voordelig vir die Asklepeïese helingskultus. Kultuspasiënte het selfs voorgeskrewe behandelings met hul dokters bespreek. Alhoewel daar geen name van dokters in die Epidauriese Asklepieion verskyn nie, was daar wel melding gemaak van sulke medici by Atene and Rhodos, Kos, Pergamum, Efese en elders. Die gereelde mediese kompetisies in die Asklepieion by Efese is genoem, en vanaf die 3de eeu v.C., het dokters wat staatswerknemers was twee keer per jaar by die Ateense Asklepieion offerandes gebring (Nutton 2004:273).

Met die opkoms van die Christendom, was die samewerking tussen sekulêre dokters en die Asklepeïese kultus aanvanklik neutraal, en tydens die vervolging van Christene het dit so gebly. Daar was egter 'n groot verskil tussen hulle benadering tot die Asklepeïese godsdienstige genesing vergeleke met die van die Hippokratiese dokters. Terwyl laasgenoemde Asklepios aanvaar het as een van hul gerespekteerde gode, het die Christene (wie se god Christus was) Asklepios onaanvaarbaar gevind. Die Christen het dus slegs 'n goddelike element in mediese genesing aanvaar wanneer dit aan sy God (nie Asklepios nie) verbonde was. Om die Asklepeïese kultus te ondersteun sou afgodery beteken, en hoe magtiger die Christendom geword het, hoe groter het die probleem geword (Ferngren \& Amundsen 1994:2977-2978). Met die aanvaarding van die Christendom as staatsgeloof in die laat 4de eeu, was die skrif aan die muur vir die Asklepeïese kultus, en geskiedkundige feite bewys dat die laaste oorblyfsels daarvan in die 6de eeu verdwyn het.

\section{Gevolgtrekking Analise van die genesingsproses}

Die feit dat die Asklepieia vir tot 10 eeue so gewild gebly het en in getal gegroei het totdat daar in amper elke stad in die klassieke wêreld ' $n$ sentrum was, is 'n duidelike bewys van doeltreffende diens. 'n Belangrike faktor was ook die feit dat genesing kosteloos beskikbaar was vir alle vlakke van die bevolking. Die uiteindelike verdwyning van die kultus was dus nie toe te skryf daaraan dat daar onbevredigende genesing plaasgevind het nie, maar wel aan teenstand van die Christendom. Nutton stel voor dat die Asklepeïese bydrae tot antieke geneeskunde wel vergelyk sou kon word met dié van die Hippokratiese skool (Nutton 2004:273).

Die kultus se genesingsproses kan gesien word in terme van twee komponente: dié wat geassosieer was met ' $\mathrm{n}$ droom of visioen en wonder-genesing gedurende die inkubasieslaap (emosionele genesing), en dié genesing wat gevolg het op raad wat deur die nag ontvang is. Laasgenoemde het konsultasies met die priester en sy personeel ingesluit - en daarna selfs die pasiënt se dokter (fisiese genesing). Heel moontlik was daar inderdaad ' $n$ oorvleueling tussen die twee prosesse. Met die beperkte bewyse wat beskikbaar is uit die literatuur en tempel inskripsies [iamata], kan 'n mens slegs spekuleer oor die moontlike aard van hierdie aspekte van die helingsritueel.

\section{Sielkundige genesing}

Vir die gemiddelde pasiënt wat bygelowig was of sterk ingestel was op godsdienstige sake, sou die inkubasieslaap 'n baie emosionele gebeurtenis wees. Nadat die pasiënt ingelig is oor moontlike ervarings wat 'n ontmoeting met die god van genesing kon meebring, sou hy of sy waarskynlik gespanne wees. Die gewyde atmosfeer van die tempel en kamer [abaton] sou verwagtinge verhoog het. Moontlike deelname deur die tempelpersoneel ter optimalisering van 'n toepaslike milieu kon 'n rol speel - daar is inderdaad bewyse dat hulle in Pergamum wel deelgeneem het aan nagtelike aktiwiteite (Van Eynde 1977:188). Ons het geen bewys dat dwelms gebruik is nie, en sal nooit werklik weet of die visioene en ervarings gemanipuleer was nie - en indien wel, hoe dit gedoen is nie. Nietemin, die totale ervaring het waarskynlik ' $n$ belangrike sielkundige impak gehad op pasiënte.

Prominent op die lys van siektes wat by Asklepieia as wonderwerke genees is, is verlamming (of swakheid), epilepsie en blindheid. Onder die moontlike oorsake van hierdie simptome (en inderdaad meer algemeen in onderontwikkelde gemeenskappe) is histerie, ' $\mathrm{n}$ toestand wat deur toegewyde psigoterapie genees kan word. Dit is dus net moontlik dat die komplekse sielkundige reaksie op ' $\mathrm{n}$ ontmoeting met die antieke god van genesing tot genesing kon lei. Ander kwale soos hoofpyn, dispepsia en sekere longkwale kon ook 'n psigosomatiese basis gehad het wat moontlik op intense sielkundige ervarings kon reageer (Gelder 1987:3-6). Ons aanname is dus dat die suiwer emosionele komponent van die inkubasieslaap gunstige terapeutiese effekte kon gehad het.

\section{Fisieke genesing}

Saam met die onmiddellike genesing wat gedurende inkubasieslaap plaasgevind het, kon heling ook die resultaat 
wees van behandeling wat voorgestel is gedurende die droom. Tempelpersoneel het ' $n$ aandeel hieraan gehad, en ons suggereer dat hulle inderdaad ' $n$ heel belangrike rol in die genesingsproses gespeel het. Hulle was deel van die terapeutiese gesprekvoering wanneer die pasiënt die god se nagtelike raad met hulle bespreek het. Dit kon aanpassings van dieet, badgewoontes en medikamente ingesluit het. Die tempel kon selfs 'n verskeidenheid mediese produkte uit hulle store verskaf. Daar was by Epidaurus geen geneeshere onder die tempelpersoneel nie, maar dit is waarskynlik dat laasgenoemdes wel kennis gehad het van die geldende genesingspraktyke. Gedurende die Grieks-Romeinse tyd was sekulêre medisyne nog in ' $n$ vroeë stadium van ontwikkeling, en het oorwegend drie modaliteite ingesluit, naamlik snykunde, medisyne en sogenaamde regimenriglyne (dieet, oefening en lewenstyl-verbetering) (verwys Sconocchia 1983), wat alles in die tempel-genesingsproses ingesluit kon gewees het. Die publikasies van geneeshere soos Hippokrates, Herophilus, Galenus en Rufus is waarskynlik algemeen deur die opgevoede publiek gelees.

Die genesing van kwale soos sere, absesse, artritis, steen, gewasse, wurms, luise en bloedsuiers, het dus waarskynlik plaasgevind volgens algemeen aanvaarde geneeskundige praktyke - met die voordeel dat dit nou ook die goddelike seën van Asklepios ingesluit het. Soos genoem, het sommige pasiënte die Asklepeïese raad met hul dokters bespreek. Dit is aangeteken dat Asklepeïese genesing soms teen die mediese praktyke gewerk het, maar in ander dokumente is die ooreenkoms tussen die twee weer beklemtoon (Edelstein \& Edelstein 1998:405, 417, 418).

\section{Literatuurverwysings}

Behr, C.A. (ed., transl.), 1971, Aristides. The Complete Works, Vol. II, The orations, Oration xxviii [Redevoerings], E.J. Brill, Leiden.

Edelstein, L., 1967, Ancient medicine. Selected papers of Ludwig Edelstein [Antieke geneeskunde. Geselekteerde artikels van Ludwig Edelstein], ed. C.L. Temkin, The Johns Hopkins University Press, Baltimore \& London.

Edelstein E.J. \& Edelstein L., 1998, Asclepius. Collection and Interpretation of the Testimonies [Asklepios. Versameling en interpretasie van die getuienisse], Vol. II, pp. 1-66, Johns Hopkins Univ. Press, Baltimore, London.

Ferngren G.B. \& Amundsen D.W., 1994, Medicine and Christianity in the Roman Empire: Compatibilities and Tensions [Geneeskunde en die Christelike geloof in the Romeinse Ryk: Versoenbaarhede en Spanning]. Augstieg und Niedergang der römischen Welt II.37.3, pp. 2957-2980.

Gelder, M.G., 1987, 'Neurosis' [Neurose], in D.J. Weatherall, J.G.C. Ledingham, \& D.A Warrell (eds.), Oxford Textbook of Medicine, Oxford Medical Publications, Oxford.

Herzog, R., 1931, Die Wunderheilungen von Epidauros. Ein Beitrag der Medizin und der Religion [Die genesingswonderwerke in Epidauros. ' $\mathrm{n}$ Bydrae tot die geneeskunde en godsdiens], Weidmansche Verlagsbuchhandlung, Leipzig.

Libanius. Selected declamations xxxiv [Libanius. Geselekteerde Redevoerings xxxiv], 23-26, transl. A.F. Norman, Loeb Classical Library Vol. II, Harvard University Press, Cambridge Mss.

Nutton, V., 2004, Ancient Medicine [Antieke Geneeskunde], Routledge, London.

Levi, P. (transl.), 1971, Pausanias. Guide to Greece [Pausanias. 'n Gids tot Griekeland], Vol. II, 27, 1-7, Penguin Books.

Retief F.P. \& Cilliers L., 2002, Snake and Staff Symbolism, and Healing [Die slang en sta simboliek en genesing], S.A. Mediese Joernaal 92(7), 553-556.

Sconocchia, S., (ed.), 1983, Scribonii Largi Compositiones [Resepte], Teubner Verlagsgesellschaft, Leipzig.

Van Eynde, I.E.M., 1977, 'Het Asklepieion te Pergamon. Een 'therapeutische centrum' in het teken van Asklepios, Orfeus en Narcissus' [Die Asklepieion te Pergamon. ' $n$ Terapeutiese sentrum in die teken van Asklepios, Orfeus en Narcissus], Tijdschrift voor Psychiatrie 19(3), 188. 